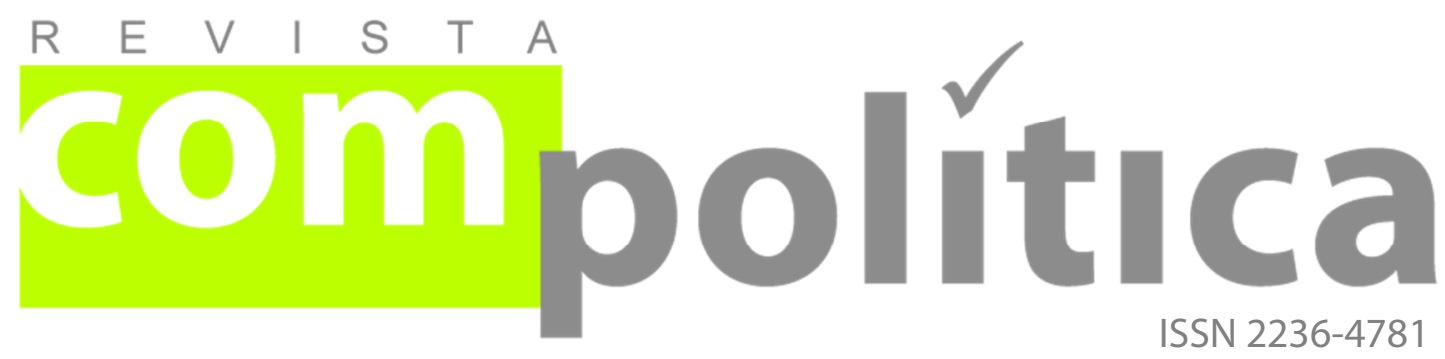

\title{
LATTMAN-WELTMAN, Fernando
}

Professor e pesquisador do Instituto de Ciências Sociais da Uerj. <flwnyc@me.com>

\section{Mídia e democracia: indeterminação e representatividade da representação}

\section{RESUMO}

Questiona-se aqui os pressupostos da chamada "crise da representação" na democracia contemporânea, e o papel específico nela desempenhado pelos modernos meios de comunicação, a partir de uma perspectiva teórica menos comprometida com os substancialismos individualista ou sociológico predominantes nas análises correntes sobre tal "crise". Para isso, procede-se a uma pequena releitura de algumas das teorias fundadoras da democracia representativa moderna, cujo objetivo é contribuir para o início de certa desmistificação da noção de "representação", tal como utilizada hoje pelos vários argumentos da "crise", mostrando que, em seus primórdios, o caráter representativo da nova ordem republicana criada no Ocidente em muito pouco - ou quase nada - se referia, de fato, a algum problema de "representação"(tal como concebido hoje). Finalmente, se esboça uma defesa da inserção institucional-política da mídia na poliarquia atual, com base numa recolocação da questão da "representatividade" para a estabilidade e a eficácia do nosso sistema, dito representativo.

Palavras-chave: Representação, Teoria Política, Mídia.

\section{ABSTRACT}

We question here the presuppositions of the contemporary democracy's so-called "crisis of representation" and the specific role of mass media on it, from a theoretical perspective not so committed to the individualistic or sociologic kinds of substantialism that seem to dominate the current analysis on that "crisis". To do so we first proceed by a reappraisal of some founding theories of modern representative democracy. The objective is to contribute to demystify the notion of "representation", as it has been used by many statements on the "crisis", by showing that in its inception the representative character of the new republican order created in Western Civilization referred itself very little - or almost not at all - to some real concern about representativeness (as it is conceived today). Finally, we sketch a different defense of the political and institutional insertion of the media in today's polyarchy based on a reassessment of the question of "representativeness" for the stability and efficacy of our political, representative, system.

Keywords: Representation, Poltical Theory, Media. 


\section{Mídia e democracia: indeterminação e representatividade da representação}

\section{[Media and democracy: indeterminacy and representativeness of representation]}

LATTMAN-WELTMAN, Fernando

$\mathrm{S}$ ão muitas as análises e interpretações correntes que, de um modo ou de outro, fazem referência a algum tipo de "crise da representação" na democracia contemporânea ${ }^{1}$.

Minha hipótese é a de que tais críticas à "crise" tendem a reificar espécies de substância, individual ou social, prévias a toda interpelação política, o que, de modo não surpreendente, acabam por reiterar tautologicamente o argumento mesmo da "crise". Ou seja: pressupõe-se a existência, prévia ao próprio jogo representativo, de interesses fundamentais da sociedade a serem representados pelo sistema; se tal representação não se faz a contento - como determinado, normativa ou teoricamente, a priori -, o sistema está em crise.

É igualmente frequente a atribuição de parte da responsabilidade pela doença à ação "deletéria" dos meios de comunicação de massa, e

\footnotetext{
${ }^{1}$ Talvez um marco inicial dessa síndrome possa ser localizado na coletânea organizada por Crozier, Huntington \& Watanuki, em 1975 (com o sugestivo título "The crisis of democracy..."). Eventualmente, a crítica se origina de problemas de eficiência das instituições - o que, obviamente, é muito diferente de uma questão de "representatividade", em termos conceituais mais precisos -, mas tudo acaba refluindo para o leito comum da "crise de representação" (seja de modo retórico e intencional, seja espontânea e "gravitacionalmente"). Aqui, porém, vou me restringir ao tema de uma possível crise de representatividade, apenas. De qualquer modo, agradeço às críticas e sugestões de pareceristas anônimos e esclareço que, tal como eles, não minimizo a importância de fenômenos comuns em democracias contemporâneas como absenteísmo, descrença em partidos e desprestígio de representantes. Apenas discordo da interpretação dominante de que tais processos sejam tão facilmente diagnosticáveis como reais problemas de representatividade, ou desafios às formas instituídas de "representação" no que tange especificamente a este tema.
} 
ao modo como estes tenderiam a invadir, ou a usurpar, contemporaneamente, outras esferas de intermediação e/ou formação de identidades políticas - ou "culturas cívicas" consideradas mais legítimas, ou apropriadas.

Este trabalho pretende questionar esses pressupostos $\mathrm{e}$ predisposições com base numa tentativa de recolocação dos termos do debate "mídia X representação", a partir de uma perspectiva teórica menos comprometida com os substancialismos individualista ou sociológico predominantes nas análises correntes sobre a tal da "crise".

Para isso, porém, será preciso, primeiro, alinhavar as principais formas de diagnóstico de tal "crise", de modo a circunscrever os aspectos em que a mídia pode ser nela responsabilizada.

Em seguida, procederei a uma pequena releitura de algumas das teorias fundadoras da democracia representativa moderna. O objetivo aqui é contribuir para o início de certa desmistificação da noção de "representação", tal como utilizada hoje pelos vários argumentos da "crise", mostrando que, em seus primórdios, o caráter representativo da nova ordem republicana criada no Ocidente em muito pouco - ou quase nada - se referia, de fato, a algum problema de "representação" (do modo como se pensa hoje, com tanto ressentimento) ${ }^{2}$.

Finalmente, vou esboçar uma defesa da inserção institucionalpolítica da mídia na poliarquia atual, com base numa recolocação da

\footnotetext{
${ }^{2}$ Divergindo do diagnóstico pessimista geral sobre a democracia representativa contemporânea - mas paradoxalmente reiterando alguns dos argumentos inconsistentes da "crítica" feita a ela, à Direita e à Esquerda (ou procurando deles desviar, e, portanto, aceitando os seus fundamentos normativos) - merece destaque a tentativa de resgate e ressignificação do conceito levada a efeito por Nadia Urbinati (2006a), cujo argumento teve uma versão resumida, em português, publicada na revista Lua Nova, no mesmo ano (URBINATI, 2006b). Como se verá adiante, embora compartilhe de sua posição - digamos, "partidária" - em defesa das instituições da representação, não consigo me convencer da propriedade (ou necessidade) dos fundamentos de sua "aposta".
} 
questão da "representatividade" para a estabilidade e a eficácia do nosso sistema, dito representativo.

\section{Crise? Qual crise?}

Quando se ouve a expressão "crise da representação" - ou quando a ela implicitamente se faz referência, de um modo ou de outro - o que obviamente está em questão é a inexistência, a inautenticidade ou a baixa qualidade de uma relação que se estabelece, ou que deveria se estabelecer entre duas partes.

$\mathrm{Na}$ verdade, existem dois modelos fundamentais em que se pensa essa relação. Modelos cujas importantes distinções podem, no entanto, dar origem a diagnósticos - e reclamações - muito similares. O primeiro modelo pode ser chamado de individualista: baseia-se na clássica relação que se estabelece entre um "principal” e um "agente", em que o primeiro delega ao segundo uma tarefa de seu interesse e que, contudo, não pode desempenhar, ou em local onde não poderá estar presente (tendo, portanto, de ser "representado" por outro, que não a si mesmo) ${ }^{3}$. o segundo modelo pode ser chamado de coletivista (ou sociológico): trata-se da representação de interesses coletivos específicos - definidos por circunstâncias econômicas, sociais, geográficas, culturais, étnicas, religiosas, corporativas, etc. - em que, obviamente, a própria coletividade a ser representada também não pode fazê-lo por si mesma (ou por limitações institucionais, ou, pelo menos, por problemas de ação coletiva).

Assim, é possível se pensar, grosso modo, ao menos quatro problemas típico-ideais diferentes de dificuldades na representação. Enquanto os três primeiros podem se referir aos dois modelos de

\footnotetext{
${ }^{3}$ Trata-se da mesma distinção que Hobbes estabelece no Leviatãa, entre pessoas "naturais" e "artificiais". Sobre esta "teoria hobbesiana da representação", origens e desdobramentos do conceito, ver Pitkin (1967).
} 
representáveis (indivíduos ou coletividades), o quarto diz respeito, especificamente, ao segundo modelo, somente:

Problemas de mediação: os canais de representação não funcionam porque, na verdade, não há vínculos entre representados e representantes; exemplo: partidos políticos sem qualquer nitidez programática e/ou ideológica, com baixa identificação no eleitorado, e/ou cujos comportamentos, uma vez eleitos, apresentem-se com total aleatoriedade;

Problemas de distorção: os canais funcionam, há vínculos, mas a escolha do eleitorado não se traduz fiel e/ou proporcionalmente em cadeiras. Exemplo: distorções promovidas na conversão de votos em cadeiras por força de regras eleitorais defeituosas - podendo, inclusive, fazer com que candidatos mais votados percam assentos para outros de votação inferior -, ou troca-troca de deputados por partidos, afetando as bancadas originais;

Problemas de alienação: os canais podem funcionar, podem haver vínculos originalmente, a ocupação das cadeiras e postos pode ser e permanecer a mais fiel possível ao resultado das urnas, mas a força gravitacional das novas condições - morais, institucionais, conjunturais, ou mesmo "estruturais" - de execução dos mandatos, nos Poderes Executivo ou Legislativo inclusive, com a reprodução de grandes assimetrias de informação, entre eleitos e eleitores - afasta e, por assim dizer, "aliena" radicalmente os representantes de seus compromissos e/ou vínculos originais; exemplo: candidatos prometem pôr em prática determinadas políticas, se eleitos, e não as cumprem, ou porque não têm os meios institucionais de poder efetivo para isso, ou se vêem diante de súbitas crises políticas e/ou econômicas que paralisam a atividade política - como escândalos de corrupção, ou redução drástica conjuntural dos fluxos de investimento externo 
-, ou estão submetidos a forças impessoais poderosas - a "globalização", as "leis da História", ou da Providência Divina -, ou, então, porque simplesmente não se sentem moralmente forçados a isso - em função da prevalência de "caldos de cultura" dissolutos, onde não há "ética na política", ou simples desvios de caráter individual, etc.;

Problemas de articulação: para além (ou aquém) das arenas representativas formais, os interesses coletivos - mesmo os "objetivamente determinados" - não logram afirmar-se e pressionar politicamente com eficácia, por conta de processos societários que minam ou inviabilizam a produção dos necessários "capitais sociais", por exemplo: coletividades dominadas tradicionalmente pelo "familismo amoral", ou outra "cultura política" deletéria para o "civismo" ou "republicanismo".

Sem me esquecer de mencionar o caráter não necessária e mutuamente excludente dessas mazelas - o que abre a possibilidade de que algumas (ou todas) ocorram simultaneamente -, o que me interessa com essa breve tipologia é, em primeiro lugar, chamar a atenção para papéis frequentemente atribuídos especificamente à mídia na produção desses problemas.

Assim, se nos três primeiros tipos de problema - mediação, distorção e alienação - a mídia só pode operar negativamente em associação às vicissitudes próprias de outras instituições: como os partidos, o sistema eleitoral, o regimento das Câmaras e Assembleias, as leis e prerrogativas institucionais etc., no quarto e último caso justamente o que envolve mais claramente padrões de sociabilidade e de cultura política - ela bem pode ser o alvo preferencial das queixas.

Com efeito, não é difícil se ouvir dizer que, para além de causas institucionais específicas, o modo peculiar através do qual a mídia e

\footnotetext{
${ }^{4}$ Sobre a noção de "capital social”, ver Putnam (1993).
} 
suas linguagens interferem cada vez mais nas disputas eleitorais, vem tornando os partidos políticos - principal instrumento de representação política da moderna democracia - agrupamentos indistintos do ponto de vista ideológico, com programas políticos muito parecidos, recorrendo crescentemente ao marketing, à construção midiática de candidatos e à desconstrução moralista dos adversários, como formas de disputa que, por assim dizer, nivelam o jogo político por baixo. ${ }^{5}$ Mais: que tais coordenadas de mídia, alheias ao "autêntico" jogo político, não se restringem, como é mais evidente, ao jogo eleitoral, e se impõem também sobre a prática parlamentar cotidiana e o desempenho ordinário do governo, como atestam o aumento das verbas de propaganda oficial, o uso propagandístico de eventos e viagens, a criação de canais de comunicação específicos para a divulgação autônoma dos trabalhos legislativos, ou ainda a luta dos parlamentares por relatorias e a participação em comissões de grande visibilidade midiática. E tudo isso se faria, é claro, automaticamente em prejuízo da coerência e do conteúdo efetivo das deliberações ou iniciativas administrativas, num incentivo por si só evidente, não ao esforço de "suar a camisa", mas, sim, do "jogar para a plateia”.

Outro tipo de ataque à mídia, em prol do resgate da representação adequada, se faz em vistas não da sua suposta intromissão no processo mesmo da representação, como visto acima, mas, sim, no modo como minaria a própria base da substância política social coletiva, favorecendo um individualismo, ou atomização, que impediria a produção dos "capitais sociais" de confiança mútua e experiência de interação coletiva, necessários, segundo toda uma nova tradição de estudos, para a efetividade das instituições

\footnotetext{
${ }^{5}$ Já no início da segunda metade do século XX, a midiatização das campanhas era denunciada por autores como Habermas (1984). Há pouco mais de uma década, novo ataque ilustre à tv, em especial, partiu da ciência política, na pessoa de Giovanni Sartori (2001). Uma lista compreensiva de contribuições no sentido dessas críticas ou queixas extrapola em muito os objetivos deste artigo. Creio que nomes ilustres como os mencionados podem bastar, a título de ilustração paradigmática de tais perspectivas.
} 
democráticas modernas. De acordo com essa vertente crítica capitaneada pelo próprio criador do conceito, Robert Putnam - a mídia, ou melhor, a mais poderosa entre estas, a televisão, estaria afastando as pessoas das experiências, novas ou tradicionais, de associativismo e vida comunitária, o que, sem dúvida explicaria o crescente declínio do civismo na América, e algures, tal como indicariam as pesquisas relativas das últimas décadas. ${ }^{6}$

A crítica de Putnam, a rigor, retoma, em novas bases, outra, mais antiga, oriunda da Escola de Frankfurt, mas reciclada, para nossos dias, pela legião dos seguidores do que podemos chamar de vertente deliberativista, ancorada, em especial, na obra de Jürgen Habermas. Aqui não se trata propriamente de processos cumulativos - de confiança recíproca e capacidade de concertação coletiva -, mas, sim, da crença na capacidade emancipatória da atividade deliberativa, em que a interação comunicativa autônoma de sujeitos racionais pode conduzi-los a aperfeiçoamentos éticos e institucionais ${ }^{7}$. De acordo com o "primeiro" Habermas - de Mudança estrutural da esfera pública - na atual "esfera pública pós-letrada" os meios de comunicação de massa se converteram em agentes falseadores do debate e promotores de uma "esfera pública plebiscitário-aclamativa" (HABERMAS, 1984).

Mas, afinal, o que possuem em comum todas essas críticas, tão ciosas da autenticidade da representação?

Seja na operação de um modelo individualista - eleitor X eleito - ou na evocação de um "principal" coletivo, malgrado a maior ou menor sofisticação da crítica, o que me parece sempre presente na argumentação é uma espécie de substantivização do interesse a ser representado: como se tratasse sempre de um interesse, individual

\footnotetext{
${ }^{6} \mathrm{O}$ argumento acusatório de Putnam é desenvolvido em sua obra de 2000, Bowling alone. Para críticas do mesmo, ver: Norris (2000) e, em nosso contexto, Gomes (2006).

${ }^{7}$ Para uma crítica desse modelo, ver alguns dos artigos críticos da coletânea de Callhoun (1992). E, na linha das análises que desenvolvo aqui, mais especificamente, Lattman-Weltman (1996).
} 
ou coletivo, cuja autenticidade, integridade e/ou objetividade jamais pudesse ser colocada em questão, mesmo que por força de uma série de fatores (em geral, os mesmos cuja legitimidade a crítica não admite) os indivíduos e coletividades efetivos não consigam se ver, ou atribuir a si mesmos os mesmos traços e interesses - e que, por isso mesmo, os leva frequentemente a continuar votando nos mesmos "representantes" que insistem em não os "representar" -, ou cultivem o péssimo hábito de mudar de prioridades e interesses (numa volubilidade e inconstância comparável somente à dos próprios "maus" representantes).

Ou seja: de par com a desqualificação teórica e conceitual dos representantes, a crítica da crise tenderia sempre, paradoxalmente, a dotar os representados, individuais e coletivos, de coerência e sistematicidade totalmente idealizadas, e, o que é pior, tendente sempre à univocidade típica dos modelos, como se tal relação não pudesse conter a mais variada e potencialmente contraditória gama de "racionalidades".

A questão é: o sistema representativo precisa mesmo de tais pressupostos para operar a contento? Precisamos, sempre, para ter certeza de que vivemos em uma democracia, nos pensar e exigir de nós mesmos a máxima coerência ou univocidade de comportamento político? Nossas instituições democráticas de nada valerão, se não puderem nos enquadrar, ou reduzir, de modo a satisfazer tais belos modelos?

E se tal sistema não passar de um método para a produção de outro resultado, a rigor, totalmente independente do seu grau efetivo de "representatividade"? E se a função específica da "representatividade" for outra?

\footnotetext{
${ }^{8}$ A rigor, é o caráter metodológica e inevitavelmente artificial dos modelos explicativos - seja os do individualismo e da escolha racional, seja o das regularidades sociológicas típico-ideais - o que tais críticas esquecem e perdem, com frequência, de vista.
} 
2. Uma crítica ainda mais antiga e algumas respostas interessantes

À medida que se estende no tempo, a experiência liberal do Ocidente

- devidamente globalizada pela voracidade de sua economia e plasticidade de suas instituições - paga o preço inevitável de converter-se em seu contrário original: uma nova forma de tradição, com suas novas e problemáticas mitologias e mistificações.

Dentre estas últimas, de fato, nenhuma parece mais multifacetada e de difícil domesticação intelectual do que aquela que se constrói em torno da palavra "representação".

Se a origem das instituições representativas se perde no tempo, não constituindo propriamente uma inovação específica da nova ordem produzida a partir da dissolução do Antigo Regime (MANIN, 1997; PITKIN, 2006a, 2006b), o peso simbólico da expressão no processo de legitimação das formas políticas contemporâneas não pode (infelizmente) ser desprezado. É em torno da representação, seus limites e pré-requisitos, que se desenvolvem muitos dos embates ideológicos atuais acerca dos limites e potenciais utópicos da democracia.

Com efeito, é justamente o caráter hoje de certo modo hegemônico da expressão "democracia" - em grande medida, por força do colapso da alternativa socialista, ao final do século XX - o que, de modo não exatamente paradoxal, faz refluir para o interior mesmo da arena de debates entre os "democratas" as mesmas queixas e expectativas ideais - e seus consequentes desdobramentos teóricos e ideológicos - que, no passado, cindiram o campo liberal em duas ou mais correntes principais antagônicas. 
Não é de se espantar, portanto, que aqui e acolá, nos recantos dessa grande arena, ecoem ainda os ataques rousseaunianos à instituição mesma da representação política moderna, tal como esta se desenvolvia à época do genial pensador suíço - em especial, na Inglaterra - o que, segundo ele, era a negação do princípio radical de soberania do povo por ele defendida: "una, indivisível e inalienável"9. O povo inglês, dizia Rousseau, ilude-se pensando ser livre, ao votar e eleger seus representantes: sua liberdade se restringe ao momento solitário do voto; a partir daí a soberania de fato passa às mãos dos ditos representantes, estes sim doravante livres para deliberar "em nome" dos ingleses, mas de acordo com suas consciências e seus próprios interesses particulares.

Ora, a legitimidade que Rousseau negava ao Parlamento inglês, e a qualquer outro formado do mesmo modo, era, porém, a mesma que, aparente e significativamente, concedia à sua "assembleia", onde os cidadãos exerceriam, de acordo com seu Contrato Social (1762), a soberania autêntica, coerentemente definida por sua indivisibilidade e inalienabilidade. Ou seja: seria legítima a soberania da assembleia que delibera e governa na "democracia direta" de Rousseau - porque nela não haveria hiato, e, portanto, risco de desvio, entre a "vontade geral" e suas deliberações. Seria o próprio soberano quem deliberaria em seu nome, e não um grupo - ou casta - de eleitos. Não haveria, de fato, representação alguma. Primeiro, por ser desnecessária; segundo, por ser (ao menos potencialmente) falseadora da "vontade geral".

Mas, por que atribuir tal autenticidade superior à deliberação da assembleia? Afinal, desde Platão sabemos que mesmo a ágora mais livre e igualitária precisa de meios para se proteger dos caminhos incertos e equívocos da doxa. De fato, quem pode garantir que a

\footnotetext{
${ }^{9}$ A originalidade de Rousseau, nesta concepção de soberania, é, obviamente, disputável. 0 mesmo argumento já aparece presente, pelo menos em Hobbes. 0 que talvez Rousseau tenha trazido de novo, a esse respeito, foram as consequências radicais de tal soberania.
} 
deliberação mais aparentemente justa e sábia de uma assembleia livre não está sujeita à persuasão retórica - e arbitrária - de algum sofista competente $?^{10}$ Como se pode ter certeza de que a deliberação teoricamente mais pura, obtida de forma mais lícita, e pelos interlocutores mais honestos e sinceros - se pudéssemos estar seguros de tudo isso - é, mesmo assim, a mais condizente com o mais elevado interesse público, com a mais perfeita "vontade geral", e não, na verdade, com alguma vontade particular, não imediatamente perceptível, ou bem ou mal disfarçada?

Pode-se argumentar, realmente, que a "vontade geral" e sua constituição - pelo soberano em assembleia -, a rigor, não deve ser confundida com as deliberações particulares deste mesmo soberano enquanto "governo" (MANIN, 1997). Ou ainda que talvez Rousseau não quisesse, na verdade, ir tão longe com sua crítica. Afinal, além de não ser suficientemente preciso - no Contrato Social - com relação aos potenciais regeneradores da "deliberação", é possível se perceber, nos capítulos finais da obra, certo ceticismo do próprio autor com relação à viabilidade de seu modelo ${ }^{11}$. Ou seja: é possível ler-se o Contrato, não tanto como a grande defesa positiva do assembleísmo e da democracia direta, mas, sim, muito mais, como a crítica radical, também, da representação, em busca da fundamentação para uma pólis afinal legítima (após séculos de acidentes e embustes institucionais). Uma crítica que, ao mesmo tempo, apontava os limites intransponíveis à legitimação do sistema político que começava a se desenvolver de forma revolucionária contra o Absolutismo - com grande sucesso, já, cerca de um século antes, na mesma Inglaterra - e que, no entanto, apontava já, de modo contraditório, para a solução teórica do problema com a proposição

\footnotetext{
${ }^{10}$ Ainda mais, é claro, sem a garantia da presença profilática de algum mestre em dialética, algum Sócrates, na ágora.

${ }^{11}$ De fato, fica difícil imaginar um personagem tão crítico e pessimista, como o Rousseau dos Discursos, nutrindo grandes esperanças e simpatias por assembleias e outros artifícios mundanos ("demasiadamente humanos") de tomada de decisão.
} 
da controvertida noção de "vontade geral", numa acepção bastante diversa daquela sugerida, à primeira vista, pela defesa do assembleísmo (como veremos adiante).

Seja como for, o fato é que desde então, ao ataque de Rousseau, seguiu-se a proliferação dos movimentos sociais e políticos voltados à superação não apenas do Absolutismo, mas também do sistema representativo moderno - ou, ao menos, dos limites à sua legitimação -, de par com as consequentes elaborações teóricas que buscaram traduzir os primeiros, normativa e operacionalmente.

Foi assim com a Revolução Francesa, primeiro grande cataclismo atribuído - talvez injustamente - ao impacto da crítica de Rousseau, entre outros. E cujos desdobramentos se fizeram notar, também na teoria moderna da representação. Seja do outro lado do Reno, seja do outro lado da Mancha.

Como o célebre Discurso aos eleitores de Bristol registra, já em 1774, ano de sua reeleição para o Parlamento inglês - e, portanto, quinze anos antes da eclosão da Revolução em França, tão duramente criticada por ele -, se é possível falar-se de uma teoria da representação política em Edmund Burke, ela já se encontrava, ao menos, razoavelmente madura em seus princípios básicos, na mente do chamado fundador do conservadorismo moderno. É justamente por isso, aliás - para fazer mais justiça à corrente de pensamento político atribuída a Burke - que acredito ser preciso referenciar tal "teoria" menos à criatividade intelectual do autor e mais à sua excelência retórica e consequente fidelidade ao espírito das tradições ideológicas que se reciclavam na Inglaterra, cerca de cem anos após a relativa estabilização política e institucional da monarquia representativa inglesa, com a vitória da chamada Revolução Gloriosa $^{12}$ :

\footnotetext{
${ }^{12}$ Não por acaso, segundo Halloran (1976), de acordo com a tradição clássica, o retórico seria exatamente “... uma pessoa que internalizou tudo de melhor da
} 
O Parlamento não é um congresso de embaixadores que defendem interesses distintos e hostis, interesses que cada um de seus membros deve sustentar, como agente e advogado, contra outros agentes e advogados, mas uma assembléia deliberativa de uma nação, com um interesse: o da totalidade, onde o que deve valer não são os interesses e preconceitos locais, mas o bem geral que resulta da razão geral do todo. Elegei um deputado, mas quando o haveis escolhido, ele não é o deputado por Bristol e sim um membro do Parlamento. Se o eleitor local tiver um interesse ou formar uma opinião precipitada, que claramente se oponham ao bem-estar real do resto da comunidade, o deputado, no assunto em pauta, deve se abster, como os demais, de qualquer gestão para levá-lo a cabo (BURKE, 1990, p. 29).

Vemos aqui, claramente, uma defesa do parlamento - órgão máximo do sistema representativo - feita não na linguagem da teoria, mas no discurso político ordinário, e cuja legitimidade, porém, não parte de alguma suposta conexão necessária entre representantes e representados - cuja plausibilidade é negada peremptoriamente pelo assembleísmo de estilo rousseauniano -, mas sim, paradoxalmente, da total autonomia que não apenas possuem, mas devem possuir os representantes diante de seu povo. Ao contrário da denúncia rousseauniana do particularismo inerente ao processo de representação moderno - particularismo que deveria ser, no essencial, cancelado pela assembleia atuando democrática e diretamente -, o que vemos no discurso de Burke a seus eleitores é a deslegitimação do mesmo particularismo com uma profissão de fé na autonomia decisória dos representantes. Não há, portanto, de acordo com Burke, fraude alguma na representação (no máximo, apenas um mal-entendido): não cabe mesmo aos representantes do povo representá-lo em suas particularidades (por isso, não faz diferença se aqueles, de fato, não podem fazê-lo); mas, sim, decidir pelo segundo

cultura, e que pode aplicar esta sabedoria no foro público, influenciando seus concidadãos a pensar e a agir em questões particulares de acordo com sua herança comum. Num sentido muito concreto, o orador clássico servia como uma voz da continuidade cultural". (HALLORAN, 1976, p. 235). 
- "querer" por ele - numa assembleia livre, independente e soberana, tendo em mente não a advocacia desta ou daquela causa particular, mas o interesse público maior da Nação (para não mencionar, de novo, a tal da "vontade geral").

Mas, então, se é assim, voltamos à estaca zero? Da idealização da assembleia rousseauniana à do Parlamento? Em que a deliberação aqui será necessária e qualitativamente melhor do que na outra? Seria possível, ainda, admitir o argumento aristocrático acerca da superioridade cultural e independência econômica como fatores de aprimoramento das deliberações de uma assembleia de "eleitos" (tal como, de fato, ainda eram as Casas do Parlamento inglês)? Muito pelo contrário: não haveria justamente o risco, por suas condições de origem, ou de prerrogativas adquiridas, de se distanciarem demais os ditos "representantes" frente aos interesses mais prementes do povo?

Sem dúvida. Burke admite-o, mesmo que indiretamente. Logo em seguida ao trecho anterior ele diz:

Ser um bom membro do Parlamento é, [...] uma tarefa difícil; especialmente neste momento em que existe uma facilidade tão grande de se cair nos perigosos extremos da submissão servil e do populismo. ${ }^{13}$ É absolutamente necessário, mas extremamente difícil unir a circunspecção com a firmeza. Somos agora deputados por uma rica cidade comercial; mas esta cidade não é, contudo, senão uma parte de uma rica nação comercial cujos interesses são variados, multiformes e intrincados. Somos deputados de uma grande nação que, contudo, não é senão parte de um grande império, expandido por nossa virtude e nosso destino, aos limites mais longínquos do Oriente e do Ocidente. Todos esses vastos interesses devem ser

\footnotetext{
${ }^{13}$ A referência à "submissão servil" é devida, provavelmente, às dificuldades de relacionamento entre as Casas e a Coroa, naquela quadra da vida política inglesa. Quanto à menção ao "populismo" - para além de arriscada liberdade de expressão do tradutor brasileiro - pode com igual risco ser creditada a radicalismos opostos aos do "servilismo", igualmente denunciado por Burke, e que ficariam manifestos em conjuntura muito posterior, a das Reflexões sobre a Revolução na França (Cf. LATTMAN-WELTMAN, 2009).
} 
considerados, comparados e, se possível, reconciliados (BURKE, 1990, p. 30).

Se os membros do Parlamento (como os de qualquer outra assembleia) podem ter seu juízo turvado, ou desviado, por forças externas e estranhas ao processo deliberativo coletivo e autônomo daí a dificuldade para ser um "bom parlamentar" -, não obstante é preciso atentar para a especificidade institucional da assembleia de representantes de uma nação moderna quando se atribui a esta a prerrogativa de decidir assuntos que dizem respeito a uma gama extremamente complexa e diversificada de interesses.

Se há alguma representatividade nesta assembleia, ela não se mede pela congruência estatística entre as posições defendidas pelos representantes e as manifestações - ou "instruções" - claras e peremptórias das vontades parciais agregadas dos representados. $\mathrm{Na}$ verdade, como o próprio Rousseau faria questão de demonstrar, tal eventual mosaico de posições, e sua correspondência fiel no voto dos parlamentares, não pode jamais ser confundido com a "vontade geral", e nada significa senão a expressão da formação, através da deliberação e suas regras, de maiorias e minorias contingentes, agrupadas mais ou menos ad hoc em função de qualquer assunto específico. Sendo a regra da maioria apenas isso: uma regra para a produção de uma decisão. Um método.

É em nome do que julga, de fato, como sendo o parâmetro real para juízo do comportamento político consequente - o "bem geral" do povo - que Burke defende não a imposição ao representante de rígidos mecanismos imperativos de fidelidade à vontade do eleitor particular, a sua transformação em mero "advogado", mas, sim, a autonomia do representante para que, entre seus pares, nas condições específicas de funcionamento do Parlamento - condições definidas por regras, tradições e honrarias concretas, historicamente 
legadas por gerações de ingleses ${ }^{14}$ - ele possa discernir com outro tipo de razão: a "razão geral do todo".

A representatividade dos representantes, nesta chave, só poderia ser medida, a rigor, em termos históricos, pelo resultado de sua ação ao longo do tempo. Se, por um lado, esta avaliação, a posteriori, não pode, também, cancelar eventuais particularismos - já que a História, mesmo com "H" maiúsculo, só adquire significado político a partir, igualmente, de alguma perspectiva - por outro lado, é a confiança, digamos, protossociológica de Burke na razão política das tradições e do (bom) senso comum - construção coletiva e adaptativa levada a efeito "naturalmente" pelas gerações - o que lhe permite apostar no processo deliberativo institucionalizado do Parlamento (e na sua própria retórica a respeito).

Sem dúvida que essa solução soaria menos que precária para ouvidos rousseaunianos (para quem a tradição e o senso comum são exatamente o problema, e o ponto de partida).

De qualquer modo, o que ressalta também na argumentação de Burke - para além, ou aquém da problemática específica da representação - é o caráter instrumental da deliberação parlamentar como método colegiado de tomada de decisão para problemas complexos (para grandes "nações e impérios"). E, de modo coerente com a trajetória institucional britânica da época, suas novas tradições e o método (burkeano) de análise, mas, acima de tudo, em vista das ameaças de retrocesso político que assomavam no horizonte, para seu partido, impunha-se também a defesa estratégica - rigorosamente política - da Casa dos representantes do povo. Se não exatamente, porque "representantes", ao menos enquanto históricos oponentes do Absolutismo e do papismo, e defensores das

\footnotetext{
${ }^{14}$ E não exatamente, portanto, as ditas "condições ideais do discurso".
} 
liberdades a que se acostumavam seus concidadãos nos últimos cem $\operatorname{anos}^{15}$.

Já de volta ao Continente, e do outro lado do Reno, porém, as condições políticas eram bem outras. Se na Inglaterra era possível desconfiar das novidades francesas, com base numa história pregressa de revoluções, guerras civis e experimentações diversas com o arbítrio e as novas liberdades, na pequena cidade prussiana de Königsberg, era mesmo inevitável que o impacto da Revolução e suas ideias motivassem outros tipos de reflexões, mobilizando paixões e carências bem diversas.

A obra política de Immanuel Kant pode, com efeito, ser lida como um tremendo esforço especulativo com o objetivo de dar sentido e precisão formal a tais revoluções intelectuais, políticas e sociais que se desenrolavam no Ocidente (e das quais pouco mais se poderia esperar, a princípio, no complicado e relativamente retardatário contexto alemão da época).

Nesse sentido, ele retoma a preocupação original de Rousseau, com a legitimidade da ordem, mas, de certo modo, "resolve" a contradição inerente à proposição da "vontade geral" - feita por aquele, em problemática associação a um mecanismo deliberativo específico, a assembleia, onde tal vontade muito possivelmente podia ser confundida com a simples vontade contingente da maioria - ao retomar, por assim dizer, o cerne da argumentação hobbesiana sobre o contrato original, na noção específica de Estado de Direito:

Um Estado (civitas) é a união de um conjunto de homens sob as leis do direito. Na medida em que essas leis são necessárias a priori e deduzidas dos conceitos de direito externo em geral (isto é, não provêm do seu

\footnotetext{
${ }^{15}$ Não seria muito distinta a raiz política conjuntural de outro famoso discurso de Burke, produzido poucos anos antes deste - Reflexões sobre as causas do descontentamento atual - e onde se encontra uma das mais brilhantes defesas da instituição partidária.
} 
estabelecimento positivo), a forma do Estado é a de um Estado em geral, isto é, a idéia do estado como ele deve ser segundo os princípios puros do direito. Essa idéia serve de padrão (norma) para a efetiva união dos homens em repúblicas (KANT, 1990, pp. 78-9).

O que para Hobbes se colocava como uma "opção" racional diante da perspectiva insuportável do "Estado de Natureza", da "guerra de todos contra todos" - a saber, o Contrato, (re)fundador da ordem e da segurança - era para Kant a ideia incontornável sob a qual assentava não apenas a possibilidade da mesma ordem, mas também a do direito e da justiça, com base em imperativos universais e racionais a priori (ou seja, independentes de qualquer circunstância empírica contingente).

É como se, através de sua crítica transcendental, Kant tivesse divisado a ideia que movia não apenas as reflexões parciais - e geniais - de seus predecessores contratualistas e iluministas, mas também o próprio sentido do movimento revolucionário dos povos ocidentais, na luta que acabou levando à construção paulatina do Estado Moderno, através de guerras civis e religiosas, com a superação da ordem feudal e do próprio Absolutismo (parceiro inicial e inimigo posterior do moto revolucionário) ${ }^{16}$.

E é exatamente este Estado de Direito, submetido à soberania impessoal da Lei, o que caracterizaria a "república", única forma legítima e duradoura de ordem política, segundo Kant:

As formas do Estado são apenas a letra da legislação originária da sociedade civil, e podem permanecer - já que pertencem aos mecanismos da Constituição do Estado - enquanto forem encaradas, por meio de velhos costumes (e, portanto, apenas subjetivamente), como necessárias. Contudo, o espírito daquele contrato

\footnotetext{
${ }^{16}$ Frise-se, por favor, o "como se" (e o risco calculado que assumo aqui, diante das importantes ressalvas que se deve fazer a esse tipo de especulação históricofilosófica, conforme nos alerta Skinner (1988)). Sobre o "papel” histórico do Absolutismo nesse grande enredo épico, ver, por exemplo, Koselleck (1999).
} 
originário [...] acarreta para a autoridade constituída a obrigação de conformar a forma de governo à idéia do contrato e, por conseguinte, de reformá-lo de maneira contínua e gradual, se isto não puder ser feito de uma só vez. Dessa maneira, o Estado tomará a forma da única Constituição legítima, a saber, a república pura. [...] Essa Constituição é a única Constituição política duradoura, na qual a lei é autônoma e não está vinculada a nenhuma pessoa em particular. [...] Toda república verdadeira é e não pode ser outra coisa senão um sistema representativo do povo, para a defesa dos seus direitos. Essa defesa se faz em nome do próprio povo, através da união de todos os cidadãos, por meio de seus representantes (KANT, 1990, pp. 78-9).

E assim, se nesse registro Kant pôde resgatar do conceito rousseaniano o seu sentido transcendental - ou seja: a "vontade geral" como condição de possibilidade de qualquer vontade política contingente e, no entanto, universalmente legítima: regra do jogo, Império da Lei, Estado de Direito; dando, portanto, ao "contrato" o seu sentido preciso de pressuposto incontornável para a legitimação da Ordem política moderna ${ }^{17}$-, por outro lado, expurgou dele, sem remissão, qualquer legitimidade singular para a "democracia direta", de tipo assembleísta.

Afinal, o que é uma "república”, para Kant?

Em seu artigo sobre a "Paz perpétua", ele explicita a diferença que existe entre esta e a "democracia":

Para que não se confunda a Constituição republicana com a democrática (como é comum acontecer), deve-se notar o seguinte. As formas de um Estado podem ser distinguidas segundo as pessoas que possuem o poder soberano, ou segundo o modo de exercício do poder sobre o povo por parte do soberano, seja ele quem for. A primeira distinção diz respeito à forma de domínio (...). Existem apenas três modalidades possíveis: a autocracia, na qual um possui o poder soberano; a aristocracia, na qual alguns se associam para juntos possuírem tal poder; ou a democracia, na qual todos aqueles que constituem a sociedade possuem o poder

\footnotetext{
${ }^{17}$ Encerrando, por assim dizer, com as intermináveis discussões bizantinas sobre o problema do momento histórico, ou ideal, de "assinatura" do Contrato Social.
} 
soberano. Podem ser caracterizadas, respectivamente, como o poder de um monarca, da nobreza ou do povo. A segunda distinção diz respeito à forma de governo, ou seja, à maneira pela qual o Estado utiliza o seu poder. Essa maneira é baseada na Constituição, que é o ato da vontade geral através do qual a multiplicidade de pessoas torna-se uma nação. Desse ponto de vista o governo ou é republicano ou é despótico. O republicanismo é o princípio de organização do Estado que estabelece a separação entre o poder executivo (o governo) e o legislativo; o despotismo é o da execução autônoma pelo Estado das leis que ele mesmo decretou. Assim, num despotismo, a vontade política é administrada pelo governante como se fossa a sua própria vontade. Dentre as três modalidades de Estado, a da democracia, propriamente falando, é necessariamente um despotismo, porque ela estabelece um poder executivo no qual 'todos' decidem por - ou mesmo contra - um que não concorda; ou seja, 'todos', que não são exatamente todos, decidem, e isto é uma contradição da vontade geral, consigo mesma e com a liberdade (KANT, 1990, pp. 78-9).

O que define a superioridade da república - e seu sistema representativo - portanto, não é de modo algum a qualidade da representação empírica que se produz contingentemente no sistema, mas a clara separação de poderes que impede o despotismo: a execução autônoma das leis por quem as decretou. O que se representa, nesta república, é, primordialmente, a ideia da vontade geral: da lei que não se subordina a nenhuma vontade particular. E é somente essa representação que pode pleitear para si legitimidade universal a priori.

Não deixa de ser curioso que talvez a formulação liberal política mais perfeita da nova ordem representativa e republicana se aproxime tanto dos efeitos institucionais do pensamento político kantiano, discordando, porém, tão claramente, no que diz respeito a suas premissas e preocupações. Refiro-me à teoria da representação tornada pública nos Artigos Federalistas, por Alexander Hamilton, James Madison e John Jay, no esforço de obtenção da ratificação da Constituição Americana de 1787. 
Partindo não propriamente da possibilidade da "vontade geral", mas, ao contrário, da inevitabilidade das facções, os chamados founding fathers da mais longeva república moderna concluem por uma "representação" que, acima de tudo, é também parte constitutiva de um grande arranjo de checks \& balances. Seus objetivos principais inequívocos são, pura e simplesmente, a governabilidade e a concertação política de uma federação de estados relativamente autônomos, e, last but not least, a prevenção de qualquer tirania majoritária inclusive - mediante um eficiente equilíbrio de poderes.

Retomando o clássico argumento do contratualismo lockeano, como justificativa para a superação do "Estado de Natureza" e a passagem para a "Sociedade Civil" - a obtenção da Justiça imparcial -, os federalistas não deixam dúvidas com relação às limitações políticas postas à efetividade da liberdade. Mormente em Estados marcados pela igualdade de condições humanas. Nas palavras de Madison:

\begin{abstract}
Não é possível que um homem seja juiz na sua própria causa, porque o seu interesse influiria decerto sobre o seu juízo e corromperia talvez a sua integridade. Pela mesma e talvez mais forte razão, não deveria uma assembléia de homens ser ao mesmo tempo parte e juiz; mas os atos mais importantes da legislação que outra coisa são senão juízos pronunciados não só sobre os direitos de um indivíduo, mas sobre os de uma grande parte dos cidadãos? Que outra coisa são os legisladores de todas as classes senão advogados e partes em todas as causas que julgam? (MADISON ( 0 Federalista), 1979, p. 96).
\end{abstract}

Apesar disso, a compreensão da differentia specifica republicana não difere em essência daquela de Kant:

Da simples enunciação do que acabamos de dizer se conclui que uma pura democracia, composta de um pequeno número de cidadãos, que se reúnem todos e governam por si mesmos, não admite remédios contra as desgraças da facção. [...] Uma república, quero dizer, 


\begin{abstract}
um governo representativo, oferece um ponto de vista diferente e promete o remédio que se deseja. [...] A república aparta-se da democracia em dois pontos essenciais; não só a primeira é mais vasta e muito maior o número de cidadãos, mas os poderes são delegados a um pequeno número de indivíduos que o povo escolhe (MADISON (O Federalista), 1979, pp. 97-8).
\end{abstract}

Aqui logo ressalta uma qualificação de ordem física que distinguiria a nova experiência norte-americana, e, de certo modo, estaria na base do otimismo com que os articulistas encaravam a obra original de engenharia política de si e de seus pares: as dimensões territoriais e o arranjo federalista de seu país.

Acima de tudo, entretanto, é novamente reiterado, ao final do artigo $n^{0}$ 10, o caráter estritamente político da solução, tirada da "própria natureza da república", esse cenário próprio da liberdade, onde não se pode evitar o mal do facciosismo, mas onde este pode ser controlado pelos mecanismos dos "freios e contrapesos": "Assim, a extensão e a sábia organização da União oferecem-nos, contra os males a que está sujeito de ordinário um governo republicano, um remédio tirado da própria natureza desse governo [...]" (MADISON (O Federalista), 1979, p. 100).

Fica evidente, após esta rápida e superficial panorâmica de autores seminais e comprometidos com vigorosas tradições políticas contemporâneas, o quanto a consagração das modernas repúblicas ou monarquias constitucionais - representativas pôde, ao menos originalmente, prescindir de quaisquer garantias (algo neuróticas) com relação à sua efetiva representatividade.

Por que, então, continuamos - hamletianamente - aguardando ansiosos a aparição do fantasma da representação autêntica?

Como podemos nos liberar de tal fixação? 
3. Em direção à democracia "pós-schumpeteriana" (ou, de como parei de me preocupar com a crise e - quase - deixei o conceito de representação para lá)

Não cabe, aqui, retomar as possíveis razões históricas, mais ou menos profundas que nos legaram essa síndrome de carência representativa que acomete a tantos de nós, hoje $\mathrm{e}^{18}$.

Em linhas muito gerais, vou apenas propor - para início de debate - a substituição do diagnóstico da crise pela afirmação dos seguintes axiomas:

1) A representação como não-problema: ao contrário do que reza a boa consciência política dos críticos, sustento, portanto, que não há crise de representação alguma. Não há crise porque, até segunda ordem, nunca existiu representação, ao menos com o rigor conceitual sustentado pelos $\operatorname{críticos}^{19}$. Nunca existiu tal cidadania substantiva, sempre idêntica a si mesma, que exigisse para si, como condição sine qua nom de legitimidade para sua ordem, uma representação autêntica. A representação hoje é tão boa, portanto, quanto sempre foi, desde que estabelecida simbólica e concretamente, em nossa História, em instituições como parlamentos, partidos, governos eleitos e controlados externamente, sistemas de regras eleitorais previamente definidas, imprensa/mídia razoavelmente livre, judiciários razoavelmente autônomos, associações, sindicatos, "Império da Lei", etc.

E é por isso, também, que sigo considerando a econômica definição de Schumpeter - “o método democrático é um sistema

\footnotetext{
${ }^{18}$ Algumas boas pistas podem ser encontradas, creio eu, nos já mencionados trabalhos de Pitkin (2006), Manin (1997), e, sobretudo, Koselleck (1999).

19 É um problema similar à teoria forte da "esfera pública", do "primeiro" Habermas, e que tive a oportunidade de analisar em Lattman-Weltman (1996). Sobre a evolução da obra de Habermas, ver Maia (2006).
} 
institucional, para a tomada de decisões políticas, no qual o indivíduo adquire o poder de decidir mediante uma luta competitiva pelos votos do eleitor" (SCHUMPETER, 1961, pp. 32728) - a mais rentável para definir o nosso sistema político. Uma definição que, não por acaso, não faz menção à representação e que, por isso mesmo, também não contradiz de modo algum os traços essenciais atribuídos à nova república pelos autores mencionados acima ${ }^{20}$.

2) A democracia como mercado político: Assim, se os antigos preferiam chamar de república o que hoje, tentativamente, chamamos de democracia, com os olhos fixos nas condições essenciais de promoção de ordem, liberdade e justiça - o que para eles, talvez, já fosse resultado bastante difícil de obter e, portanto, mais do que o suficiente para a legitimação da mesma ordem -, hoje prefiro manter a denominação hegemônica nos quadros minimalistas de Schumpeter, não somente para contornar as aporias da representação, mas também para enfatizar os elementos mercadológicos e indeterminados do jogo político democrático. Menos por alguma questão de coerência ou compromisso ideológico, e mais para defender a possibilidade de uma análise política e institucional livre de pressupostos metafísicos de difícil operacionalização, como podem ser os do cidadão-eleitor racional, ou "consciente", ou das "classes dominadas", ou ainda das "comunidades excluídas", etc. Colocar a ênfase nas estratégias dos competidores, ou, alternativamente, nas condições de exercício dessa competição, ou ainda no modo como os ditos representados trocam seus votos por outras moedas, me parece já um bom meio de análise das características da política representativa contemporânea, sem os inconvenientes já mencionados.

\footnotetext{
${ }^{20}$ A despeito, inclusive, das próprias intenções iconoclastas de Schumpeter, frente aos clássicos, em seu experimento teórico e conceitual.
} 
3) A representação por equilíbrio de poderes indeterminados: do mesmo modo, a perspectiva mercadológica aqui defendida incorpora sem dificuldades as chamadas instituições e processos específicos da representação como parte de um sistema político mais amplo, cuja operação articulada configura, por assim dizer, não apenas essa grande economia schumpetereana do voto - cujo resultado agregado é alguma forma de "representação", mais ou menos indeterminada -, mas cujos "subprodutos marginais" podem ser ainda outros: inclusive, a ordem, a liberdade e a justiça impessoal dos fundadores. Por isso a representação pode, ainda, ser pensada como parte do sistema de checks \& balances, ou, mais específica e contemporaneamente, como parte essencial dos mecanismos de accountability da poliarquia.

4) Da accountability vertical à horizontal: do que foi dito acima compreende-se também que, embora, de fato, a demanda pela chamada accountability vertical pareça reiterar, ou recolocar em tela alguns dos argumentos centrais da síndrome da crise da representação - já que, sem um eleitor substantivo e atento para cobrar, recompensar ou punir o seu "agente", e um sistema partidário e eleitoral que favoreça tal identificação e reação, parece difícil falar em prestação de contas vertical ${ }^{21}$-, tal operação não precisa incorrer nos problemas de reificação já apontados. Basta observar o modo como, a rigor, não existe processo supostamente eficaz de accountability vertical que opere hoje sem a articulação desse mecanismo aos meios de produção da chamada accountability horizontal. De fato, mesmo que tais supostos processos de "punição" ou "recompensa" operem através do voto, como se diz, "de baixo para cima", eles dificilmente poderão se dar sem a interferência de controles horizontais e sua publicidade. Mais uma razão para se desconfiar

${ }^{21}$ Exemplos da velha crítica e da manipulação algo reificada da accountability vertical podem ser facilmente encontrados na atual (e, apesar de tudo, boa) literatura de reformismo político (por exemplo: Lamounier (2005) e Almeida (2006)). 
das mistificações da simplificação da relação "agente/principal" e para pensar a representação em sentido bem mais amplo e problemático.

5) Mídia como contribuição pan-óptica para a accountability: com efeito, dado o caráter estratégico da questão da publicidade preferiria dizer, visibilidade (GOMES, 2004) - todo o processo de accountability passa hoje - para desânimo dos puristas antitelevisivos, ou anti-midiáticos - pelos meios de comunicação de massa. E aqui fica ainda mais claro o caráter limitado e restritivo dos modelos substantivistas mencionados: pois o que realmente importa, a esse respeito, na intervenção política da mídia não é, simplesmente a sua instrumentalidade tradicional pressuposta: a de oferecer informação, pura, simples e fidedigna, que oriente o cálculo do cidadão, ou cidadãos "conscientes”, para que estes, aí sim, centrados em sua coerência interna, punam ou recompensem os seus "representantes" 22. Não. O modo principal de operação da mídia no processo de accountability se faz de maneira muito mais complexa: dado o caráter estratégico da visibilidade na "democracia de público" contemporânea, isto se faz muito mais através da produção do que já chamei de efeito pan-óptico, ou seja, a criação de um ambiente de visibilidade possível e razoavelmente não controlada, que pode, a qualquer momento, expor pessoas e instituições públicas ao juízo de uma corte fluída e imprevisível: algo que tentativa e precariamente chamamos de “opinião pública"23. Não importando tanto, portanto, no que se refere à prestação de contas, a presumida falta de conexão, ou de

\footnotetext{
${ }^{22}$ Essa ainda é a visão tradicional que a Ciência Política costuma ter da intervenção política da mídia, de par com as mistificações sobre a cidadania, individual ou coletiva. Para uma visão alternativa, ver Lattman-Weltman (2003).

${ }^{23} \mathrm{O}$ que dá ao pan-óptico a eficácia de controle do comportamento, pretendido por seu criador, Jeremy Bentham, é o seu poder de internalização: o observado não sabe como nem por quem, mas apenas que a qualquer momento pode estar sendo observado em sua conduta (ou eventuais desvios). A análise clássica é de Foucault (1991).
} 
"transparência", entre "agente" e "principal" 24 já que as supostas falhas nessa "comunicação" podem ser largamente compensadas para o sistema como um todo - com os eventuais efeitos perversos inevitáveis - pelo show, ou novela, das denúncias, escândalos e flagrantes midiáticos de corrupção. Ou melhor: pelo efeito potencial de controle indeterminado que assim se pode produzir.

6) A democracia pós-schumpetereana: desse modo, se a definição de Schumpeter já nos coloca em novo terreno metodológico, onde o que efetivamente define a natureza do nosso regime é, por assim dizer, a interpelação competitiva que os candidatos à elite política fazem aos detentores da moeda central para o ingresso nesta mesma "ágora" - o voto - a introdução consequente da mídia no processo (e sem as armadilhas idealistas da reificação cidadã) pode nos permitir, inclusive, pensar o que arriscadamente chamaria de "democracia pós-schumpetereana": aquela em que não apenas se apela a eleitores razoavelmente - ou tendencialmente - indeterminados, mas, a rigor, busca-se criar tais eleitorados, contingentemente, a partir de estratégias políticas que se assenhoram não apenas das variáveis institucionais específicas de cada disputa, mas também das variáveis simbólicas específicas que podem atuar na conformação de identidades, para a arregimentação de apoios e formação de consensos, mais ou menos precários, para a luta política, eleitoral, parlamentar etc. Variáveis que, portanto, dependem de embates no campo da visibilidade pública. E onde a mídia bem pode ser uma das instituições mais estrategicamente decisivas.

Resta, porém, admito, o problema da legitimidade: e não como exigência metafísica, mas, sim, como horizonte de expectativas sobre o sistema. De fato, aqui parece que a problemática da representatividade e suas crises, pode guardar, ainda, alguma

\footnotetext{
${ }^{24}$ É claro que tal conexão frequentemente existe e é bem concreta: o velho clientelismo, o corporativismo, ou o simples lobbyismo - a tal da advocacia indesejada por Burke - que o digam. Mas qual crítico da crise vai aceitar isso?
} 
relevância. Ou seja: mesmo que não passe de um mito - ou por isso mesmo - a crise da representação não deixa de poder exercer influência sobre o grau de adesão de seus membros ao regime representativo ${ }^{25}$.

Não existiria, a princípio, solução simples para esse problema. A não ser, claro, no terreno próprio dos mitos, das mistificações, e suas formas de reprodução e alimentação coletivas, o que, na verdade, é o mesmo que dizer que o terreno de combate é o velho e conhecido campo político da retórica (ou campo da retórica política).

Assim, se a mídia pode ser a primeira instituição a reproduzir em progressão geométrica a tal crise da representação - e nesse aspecto ainda posso me colocar ao lado de seus detratores - pode ser também através dela, do uso de seus canais e linguagens, que podemos igualmente defender a legitimidade dessas mesmas velhas instituições democráticas, de quem nos mostramos, por vezes, tão ingratos.

Para tanto, contudo, seria bom contar, também, com bons desempenhos concretos destas últimas. E nesse caso, forçoso é aprimorá-las em seus desempenhos efetivos, com o auxílio de parâmetros críticos mais eficientes.

Melhores, por exemplo, do que os que repetem a síndrome crítica aqui criticada (mas isso já é outra tautologia).

\section{Referências}

ALMEIDA, Alberto. Amnésia eleitoral: em quem você votou para deputado em 2002? E em 1998? In: SOARES, G.A.D.; RENNÓ, L.R. (Orgs.), Reforma política: lições da história recente, Rio de Janeiro: Editora FGV, 2006.

BURKE, Edmund. Discurso aos eleitores de Bristol. In: WEFFORT, F. (Org.). Clássicos da Política (V.2). São Paulo: Ática, 1990.

\footnotetext{
${ }^{25}$ Embora talvez de modo não tão decisivo ou independente quanto a noção de uma suposta influência midiática indiscriminada parece sugerir (para uma reelaboração crítica de tal noção, ver, por exemplo, Lattman-Weltman (2013).
} 
CALLHOUN, Craig (Ed.), Habermas and the public sphere. Cambridge: MIT Press, 1992.

CROZIER, M., HUNTINGTON, S.P. \& WATANUKI, J. (Eds.). The crisis of democracy: report on the governability of democracies to the trilateral commission. New York: New York University Press, 1975.

FOUCAULT, Michel. Vigiar e punir. Petrópolis: Vozes, 1991.

GOMES, Wilson. Tocqueville não via tv: capital social, democracia e televisão em Robert Putnam. Paper apresentado ao XV Encontro da Compós, Bauru, 2006.

Paulus, 2004

Transformações da política na era da comunicação de massa. São Paulo:

HABERMAS, Jürgen. Mudança estrutural da esfera pública. Rio de Janeiro: Tempo Brasileiro, 1984.

HALLORAN, S.M. Tradition and Theory in Rhetoric. In: Quarterly Journal of Speech, Vol.62, pp. 234-242, October 1976.

HAMILTON, A.; MADISON, J.; JAY, J. O federalista. Coleção Os Pensadores, São Paulo: Abril Cultural, 1979.

KANT, Immanuel. Primeiros princípios da filosofia do Direito. In: WEFFORT, F. (Org.). Clássicos da Política (V.2). São Paulo: Ática, 1990.

KOSELLECK, Reinhart, Crítica e crise: uma contribuição à patogênese do mundo burguês. Rio de Janeiro: EdUerj/Contraponto, 1999.

LAMOUNIER, Bolívar. Da Independência a Lula: dois séculos de política brasileira. São Paulo: Augurium, 2005.

LATTMAN-WELTMAN, Fernando. Informação, preferências e engajamento: desventuras da influência política midiática no Brasil democrático. Paper apresentado no 37 Encontro Anual da Anpocs, Águas de Lindóia, 2013.

Edmund Burke: a estética conservadora da arte política. In: FERREIRA, L.P. et al (Orgs.). Curso de Ciência Política: grandes autores do pensamento político moderno e contemporâneo. Rio de Janeiro: Elesevier, 2009.

A esfera pública: do conceito à palavra-de-ordem - notas para uma alternativa pragmatista de intervenção na comunicação política brasileira. In: Comunicação e Política, Rio de Janeiro, V.3, n.1, pp. 160-175, 1996.

LATTMAN-WELTMAN, Fernando; ABREU, Alzira Alves; KORNIS, Monica Almeida. Mídia e política no Brasil: jornalismo e ficção. Rio de Janeiro: Editora FGV, 2003.

MAIA, Rousiley. Política deliberativa e tipologia de esfera pública. Paper apresentado ao XV Encontro da Compós, Bauru, 2006.

MANIN, Bernard, The principles of representative government. New York: Cambridge University Press, 1997.

NORRIS, Pippa. The impact of television in civic malaise. In: PHARR, S.J.; PUTNAM, R.D. (Eds.). Disaffected democracies. Princeton: Princeton University Press, 2000.

PITKIN Hanna F. The concept of representation. Los Angeles: University of California Press, 1967. 
. Representação: palavras, instituições e ideias. In: Lua Nova, São Paulo, 67, pp. 15-47, 2006.

PUTNAM, Robert. Bowling alone: the collapse and revival of american community. Nova York: Simon \& Schuster, 2000.

Making democracy work: Civic traditions in Modern Italy. Princeton: Princeton University Press, 1993.

ROUSSEAU, J.J. Do Contrato Social (e outras obras). São Paulo: Abril Cultural, 1978. (Os Pensadores).

SARTORI, Giovanni. Homo videns: televisão e pós-pensamento. Bauru: Edusc, 2001.

SCHUMPETER, Joseph A. Capitalismo, Socialismo e Democracia. Rio de Janeiro: Fundo de Cultura, 1961.

SKINNER, Quentin. Meaning and understanding in the history of ideas. In: TULLY, J. (Ed.). Meaning and context: Quentin Skinner and his critics. Cambridge: Polity Press, 1988.

URBINATI, Nadia. Representative democracy: principles and genealogy. Chicago: University of Chicago Press, 2006a.

O que torna a representação democrática? In: Lua Nova, São Paulo, 67, pp. 191-228, 2006b.

COMP(IITICA ASSOCIACCĀO BRASILEIRA DE PESQUISADORES EM COMUNICAÇẢO E POLÍTICA

Presidente: Alessandra Aldé (UERJ)

Vice-Presidente: Luis Felipe Miguel (UnB)

Secretário Executivo: Francisco Jamil Marques (UFC)

Editoras-Chefes:

Alessandra Aldé (UERJ) e Maria Helena Weber (UFRGS)

Editores Executivos:

Edna Miola (UFS), Fernanda Sanglard (UERJ), Rafael

Cardoso Sampaio (UFMG) e Viktor Chagas (UFF)

Revisoras:

Fernanda Sanglard (UERJ) e Isabele Mitozo (UFPR)

<http://compolitica.org/revista>
A Revista Compolítica é uma revista eletrônica da Associação Brasileira de

Pesquisadores em Comunicação e Política. Com periodicidade semestral, sua proposta é difundir a produção acadêmica relacionada às interfaces desses campos de estudo.

Ao citar este artigo, utilize a seguinte referência bibliográfica

LATTMAN-WELTMAN, Fernando. Mídia e democracia: indeterminação e representatividade da representação. In: Revista Compolítica, n. 4, vol. 2, ed. agosto-dezembro, ano 2014. Rio de Janeiro: Compolítica, 2014. 
